\title{
Формирование углеродных слоев методом термического разложения четыреххлористого углерода в реакторе МOC-гидридной эпитаксии
}

\author{
(C) Б.Н. Звонков ${ }^{1}$, О.В. Вихрова ${ }^{1, \uparrow}$, Ю.А. Данилов ${ }^{1}$, М.В. Дорохин ${ }^{1}$, П.Б. Демина ${ }^{1}$, М.Н. Дроздов ${ }^{2}$, \\ А.В. Здоровейщев ${ }^{1}$, Р.Н. Крюков ${ }^{1}$, А.В. Нежданов ${ }^{3}$, И.Н. Антонов ${ }^{1}$, С.М. Планкина ${ }^{3}$, М.П. Темирязева ${ }^{4}$ \\ ${ }^{1}$ Научно-исследовательский фризико-технический институт \\ Нижегородского государственного университета им. Н.И. Лобачевского, \\ 603950 Нижний Новгород, Россия \\ ${ }^{2}$ Институт фризики микроструктур Российской академии наук, \\ 603950 Нижний Новгород, Россия \\ ${ }^{3}$ Нижегородский государственный университет им. Н.И. Лобачевского, \\ 603950 Нижний Новгород, Россия \\ ${ }^{4}$ Фрязинский фрилиал Института радиотехники и электроники им. В.А. Котельникова \\ Российской академии наук, \\ 141190 Фрязино, Московская область, Россия \\ I E-mail: vikhrova@nifti.unn.ru
}

Поступила в Редакцию 15 апреля 2020 г.

В окончательной редакции 21 апреля 2020 г.

Принята к публикации 21 апреля 2020 г.

\begin{abstract}
Разработан новый метод осаждения углеродных пленок термическим разложением четыреххлористого углерода $\left(\mathrm{CCl}_{4}\right)$ в потоке водорода в реакторе MOC-гидридной эпитаксии при атмосферном давлении. Результаты исследования методом спектроскопии комбинационного рассеяния света позволяют предположить, что полученные этим методом углеродные слои представляют собой разупорядоченный нанокристаллический графит. Показана возможность использования такого углеродного слоя в технологическом цикле создания арсенид-галлиевых приборных структур оптоэлектроники (в частности, спиновых светоизлучающих диодов с инжектором $\mathrm{CoPt}$ ).
\end{abstract}

Ключевые слова: углеродные пленки, МOC-гидридная эпитаксия, GaAs приборные структуры.

DOI: 10.21883/FTP.2020.08.49629.05

\section{1. Введение}

Углеродные материалы представляют интерес для перспективных разработок по разнообразному применению в современной нано- и оптоэлектронике. Наибольшее внимание уделяется развитию новых методов получения и использования графена (однослойного и многослойного) в комбинации с приборными полупроводниковыми структурами. В частности, сочетание высокой прозрачности $(\sim 97 \%)$ с высокой проводимостью и теплопроводностью делает слои графена наиболее привлекательными в качестве проводящих и прозрачных контактов для приборов оптоэлектроники: светодиодов, фотоприемников и фотопреобразователей [1]. Прозрачные электроды обеспечивают равномерное растекание тока по поверхности полупроводника и позволяют использовать всю поверхность полупроводниковых наногетероструктур для излучения света. Графен по своим свойствам выгодно отличается от традиционно используемых прозрачных электродов из легированного титаном индий-оловянного оксида (ITO), применяющегося в дисплеях, источниках света и солнечных батареях. Прозрачные электроды на основе ITO подвержены деградации по причинам термической и химической нестабильности [1,2] и существенно поглощают свет как в ближней инфракрасной (ИК) [3], так и в синей (ультрафиолетовой) областях спектра (УФ) [4]. Следует отметить, что графен, благодаря низкому коэффициенту отражения $(0.1-2.3 \%)$, может быть также использован в качестве просветляющего покрытия [1].

Большинство работ по использованию графеновых слоев в качестве прозрачного проводящего контакта относится к гетеронаноструктурам на основе $\mathrm{GaN}$ и созданным на их основе вертикально излучающим светодиодам и фотодетекторам на УФ и видимый диапазоны излучения [1,2,5-7]. Недавно появились работы по использованию графена в качестве контакта для фотодетекторов ближнего ИК-диапазона, изготовленных на основе арсенид-галлиевых структур $[8,9]$. Как правило, для получения слоев графена используется химическое осаждение из газовой фазы (CVD-метод) на подложках из переходных металлов ( $\mathrm{Cu}, \mathrm{Ni}$ и др.). Достоинствами данного метода являются: высокая скорость осаждения графена, возможность получения больших по площади образцов и малая себестоимость. К недостаткам использования CVD-метода можно отнести высокие температуры выращивания, что не позволяет наносить слои графена непосредственно на поверхности полупроводниковых гетеронаноструктур. Для переноса слоев графена на поверхность полупроводника и последующего формирования прозрачного проводящего контакта необходимо использовать химические методы. Отмечается, 
что почти все светодиоды на основе GaN c прозрачным проводящим контактом из графена получают с применением CVD-метода с последующим „влажным“ переносом на поверхность полупроводника. Процесс переноса очень сложный и способствующий непреднамеренному и необратимому легированию или загрязнению, адсорбции, накоплению остатков химических соединений, оксидов и появлению нарушений на границе раздела графен/полупроводник, что в значительной степени отрицательно влияет на характеристики приборов. Таким образом, применение углеродных слоев (однослойного и многослойного графена) для разработки приборов наноэлектроники на основе соединений $\mathrm{A}^{\mathrm{III}} \mathrm{B}^{\mathrm{V}}$, и в частности, наиболее широко используемого полупроводника $\mathrm{GaAs}$, затруднено из-за отсутствия методов формирования углеродных слоев непосредственно на поверхности полупроводниковых структур с сохранением их свойств.

В настоящей работе впервые предложен и реализован метод осаждения углеродных (C) пленок термическим разложением четыреххлористого углерода в потоке водорода в реакторе МОС-гидридной эпитаксии (МОСГЭ) при атмосферном давлении. Одно из основных преимуществ данного метода состоит в том, что формирование углеродного слоя может быть встроено в процесс создания светоизлучающей или фотодиодной структуры и происходит в том же реакторе, что и эпитаксиальное выращивание приборных структур. На подложках $\mathrm{GaAs}(100)$ последовательно формируются все необходимые слои: буферный слой (In, Ga)As, квантовая яма InGaAs (или массив квантовых точек InAs/GaAs), спейсерный и покровный слои GaAs. Далее без выноса структуры на воздух на ее поверхности может быть сформирован углеродный слой.

\section{2. Методика эксперимента}

Методом МОСГЭ на пластинах $n(p)^{+}-\mathrm{GaAs}(100)$ и $i$-GaAs (100) были изготовлены гетероструктуры с квантовой ямой (КЯ) $\mathrm{In}_{0.15} \mathrm{Ga}_{0.85} \mathrm{As} / \mathrm{GaAs}$. Толщина покровного слоя GaAs составляла 20-30 нм. С применением метода термического разложения $\mathrm{CCl}_{4}$ в потоке водорода на поверхности изготовленных структур формировались углеродные пленки. Варьировались температура процесса от 560 до $650^{\circ} \mathrm{C}$ и время нанесения углеродной пленки (5-40 мин). В табл. 1 приведено краткое описание арсенид-галлиевых структур, изготовленных при температурах 600 и $650^{\circ} \mathrm{C}$. Аналогично были сформированы углеродные пленки на пластинах $\mathrm{Si}(111)$ при температурах 600 и $700^{\circ} \mathrm{C}$.

Были исследованы морфология, состав, структура, излучательные, оптические и электрические свойства изготовленных образцов. Использовались следующие методы: спектроскопия комбинационного рассеяния света (КРС), атомно-силовая микроскопия (АСМ), рентгеновская фотоэлектронная спектроскопия (РФЭС), спек-
Таблица 1. Технологическое описание арсенид-галлиевых гетероструктур с углеродными пленками на поверхности

\begin{tabular}{|c|c|c|}
\hline № & Описание структуры & $T_{g},{ }^{\circ} \mathrm{C}$ \\
\hline A & $\begin{array}{l}\text { Контрольная структура с квантовой ямой } \\
\text { на подложке } n^{+}-\mathrm{GaAs}\end{array}$ & 650 \\
\hline B & $\begin{array}{l}\text { Выдержка в } \mathrm{CCl}_{4} 20 \text { мин (скорость } \\
\text { потока } 7.5 \cdot 10^{-2} \text { моль/ч). } \\
\text { Структура с квантовой ямой на подложке } n^{+}-\mathrm{GaAs}\end{array}$ & 650 \\
\hline $\mathrm{C}$ & $\begin{array}{l}\text { Выдержка в } \mathrm{CCl}_{4} 20 \text { мин (скорость } \\
\text { потока } 4 \cdot 10^{-2} \text { моль/ч). } \\
\text { Структура с квантовой ямой и покровным } \\
\text { слоем GaAs : } \mathrm{Si} \text { на подложке } p^{+}-\mathrm{GaAs}\end{array}$ & 650 \\
\hline $\mathrm{D}$ & $\begin{array}{l}\text { Выдержка в } \mathrm{CCl}_{4} 5 \text { мин (скорость } \\
\text { потока } 7.5 \cdot 10^{-2} \text { моль/ч). } \\
\text { Структура с квантовой ямой на подложке } n^{+} \text {-GaAs }\end{array}$ & 600 \\
\hline $\mathrm{E}$ & $\begin{array}{l}\text { Выдержка в } \mathrm{CCl}_{4} 10 \text { мин (скорость } \\
\text { потока } 7.5 \cdot 10^{-2} \text { моль/ч). } \\
\text { Структура с квантовой ямой на подложке } n^{+}-\mathrm{GaAs}\end{array}$ & 600 \\
\hline
\end{tabular}

троскопия отражения, вторичная ионная масс-спектрометрия (ВИМС) и спектроскопия фото- и электролюминесценции.

Исследования спектров комбинационного рассеяния света проводились на установке NTEGRA SPECTRA (NT-MDT) при комнатной температуре в геометрии обратного рассеяния с использованием лазера с длиной волны 473 нм. Излучение фокусировалось $100 \times$ объективом с апертурой $\mathrm{NA}=0.95$ в пятно диаметром $\approx 1$ мкм, мощность излучения составляла 0.12 или 0.5 мВт. Время экспозиции было 300 с.

АСМ-исследования были реализованы при помощи атомно-силового микроскопа SmartSPM (AIST-NT). Оптические свойства образцов исследовались с помощью спектроскопии отражения при комнатной температуре в диапазоне длин волн от 0.18 до 1.8 мкм с использованием спектрофотометра Cary 6000i фирмы Varian.

Исследования РФЭС проводились с использованием двухкамерного сверхвысоковакуумного комплекса Multiprobe RM (Omicron Nanotechnology GmbH). Изучение структур методом ВИМС было выполнено на установке TOF.SIMS-5. Послойный анализ проводился с использованием распыляющих пучков ионов $\mathrm{O}_{2}$ или $\mathrm{Cs}$ и анализирующего пучка ионов $\mathrm{Bi}$.

\section{3. Результаты и обсуждение}

Исследования методом эффекта Холла структур с углеродными пленками, изготовленных на подложках полуизолирующего GaAs (100), обнаружили, что структуры имеют дырочный тип проводимости с достаточно высокой слоевой концентрацией $\left(4.4 \cdot 10^{12}\right.$ и $4.3 \cdot 10^{13} \mathrm{~cm}^{-2}$ для структур с температурой формирования углеродной 


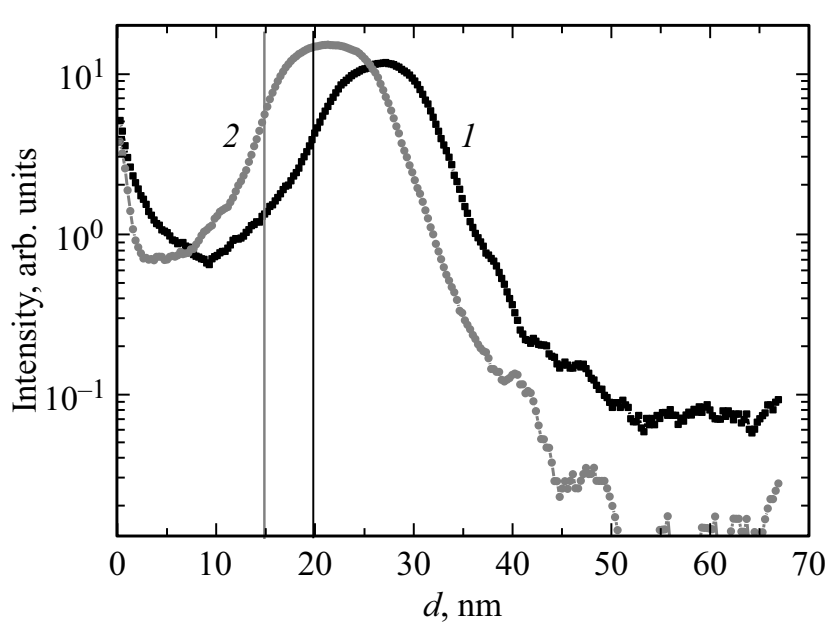

Рис. 1. Полученное методом ВИМС распределение атомов In по глубине для контрольной структуры (кривая 1) и структуры с углеродной пленкой на поверхности (кривая 2).

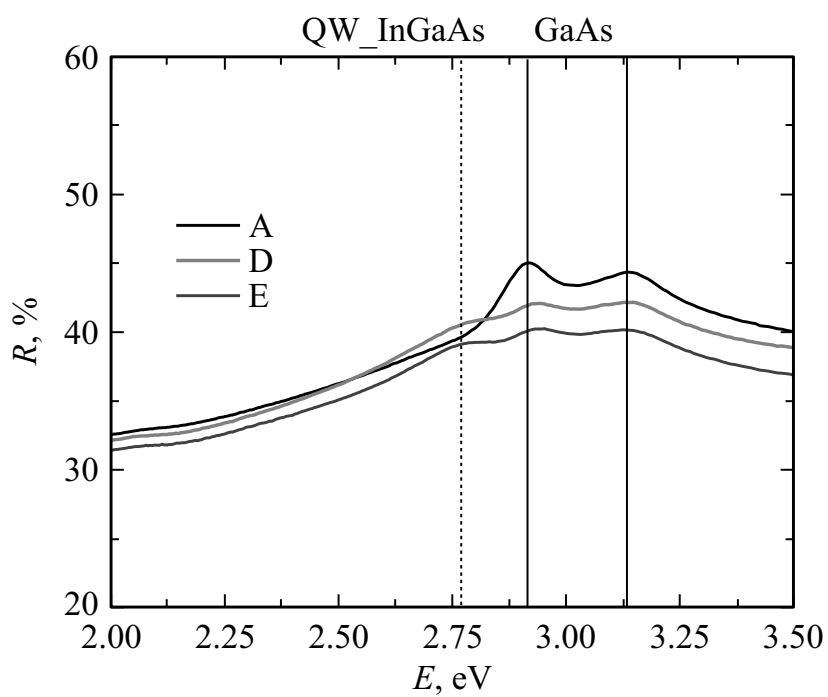

Рис. 2. Спектры отражения контрольной структуры А и структур с углеродными пленками D и Е (табл. 1).

пленки 600 и $560^{\circ} \mathrm{C}$ соответственно). С увеличением температуры формирования углеродного слоя концентрация дырок уменьшается на порядок величины и снижается их подвижность.

Дырочный тип проводимости может быть обусловлен тем, что на начальном этапе формирования углеродного слоя происходит травление покровного слоя $\mathrm{GaAs}$ четыреххлористым углеродом и легирование приповерхностного слоя [10] (углерод ведет себя в GaAs как акцепторная примесь). Поэтому в структурах могут быть два канала проводимости: сильно легированный углеродом слой GaAs на поверхности и углеродная пленка. Вначале поверхность GaAs „насыщается“ углеродом, далее происходит формирование углеродного слоя.

Сравнительный анализ послойного распределения индия в контрольной структуре и структуре с углеродным слоем на поверхности, проведенный методом ВИМС, показал, что при нанесении углеродной пленки толщина покровного слоя GaAs уменьшилась на 5-6нм. Это происходит в результате травления покровного слоя GaAs в атмосфере четыреххлористого углерода (рис. 1).

Исследования спектроскопии отражения подтвердили сохранение кристаллического совершенства покровного слоя GaAs после травления и формирования углеродной пленки. Спектры отражения (рис. 2) в области энергий квантов от 2 до 4 эВ (глубина проникновения излучения составляет $\sim 20$ нм) содержат характерный для монокристаллического GaAs дублет пиков в области энергий $E_{1}\left(2.9\right.$ э) и $E_{1}+\Delta_{1}(3.12$ эB), соответствующий переходам в направлении $\Lambda$ зоны Бриллюэна [11]. Кроме того, для структур с углеродным слоем на поверхности наблюдается пик при энергии 2.77 эВ, появление которого обусловлено отражением от слоя InGaAs (квантовой ямы). Его можно интерпретировать как пик в области энергии $E_{1}$ для слоя InGaAs, так как содержание индия в подрешетке галлия составляло не более $15 \%$. Второй пик дублета для слоя InGaAs $-E_{1}+\Delta_{1}$ не разрешается на фоне дублета от покровного слоя GaAs. Таким образом, представленные на рис. 2 спектры отражения подтверждают уменьшение толщины покровного слоя в результате травления GaAs четыреххлористым углеродом в процессе формирования углеродного слоя.

Результаты исследований углеродных пленок на GaAs (100) структурах с использованием атомно-силовой микроскопии продемонстрировали достаточно гладкую поверхность углеродного покрытия: среднеквадратичное отклонение составляет менее 0.5 нм. Обнаружено, что тонкая углеродная пленка может ложиться на подложку „морщинами“ подобно графену (рис. 3, $a$ ). Согласно данным АСМ-исследований углеродных пленок, полученных на пластинах $\mathrm{Si}$ (111), поверхность образцов покрыта очень тонкими иголочками. Ширина такой иголочки на скане $\sim 10$ нм на полувысоте, что сопоставимо с размером зонда. Невозможно определить реальный размер такой иголочки, но можно только предполагать, что она тоньше 10 нм (рис. $3, b)$. Подобные образования в литературе называют вертикальным графеном $[12,13]$, материалом, перспективным для эмиссионной электроники.

Рентгеновская фотоэлектронная спектроскопия структур показала, во-первых, формирование на поверхности GaAs углеродных слоев, и, во-вторых, значительное преобладание в них графитоподобных связей $\left(s p^{2}\right)$ над алмазоподобными связями $\left(s p^{3}\right)$. В частности, для углеродных пленок, полученных на поверхности арсенидгаллиевых структур при $600^{\circ} \mathrm{C}$ и времени формирования 20 мин, отношение $C\left(s p^{2}\right) / C\left(s p^{3}\right)$ достигало 7.6.

Результаты исследований методом КРС структур, изготовленных при температуре $650^{\circ} \mathrm{C}$, показаны на рис. 4 и отражены в табл. 2. В спектрах наблюдаются следующие линии: $G-$ основная линия для графита, $D$ - линия, обусловленная присутствием дефектов в графите/графене. Отношение интенсивностей линий $D$ 

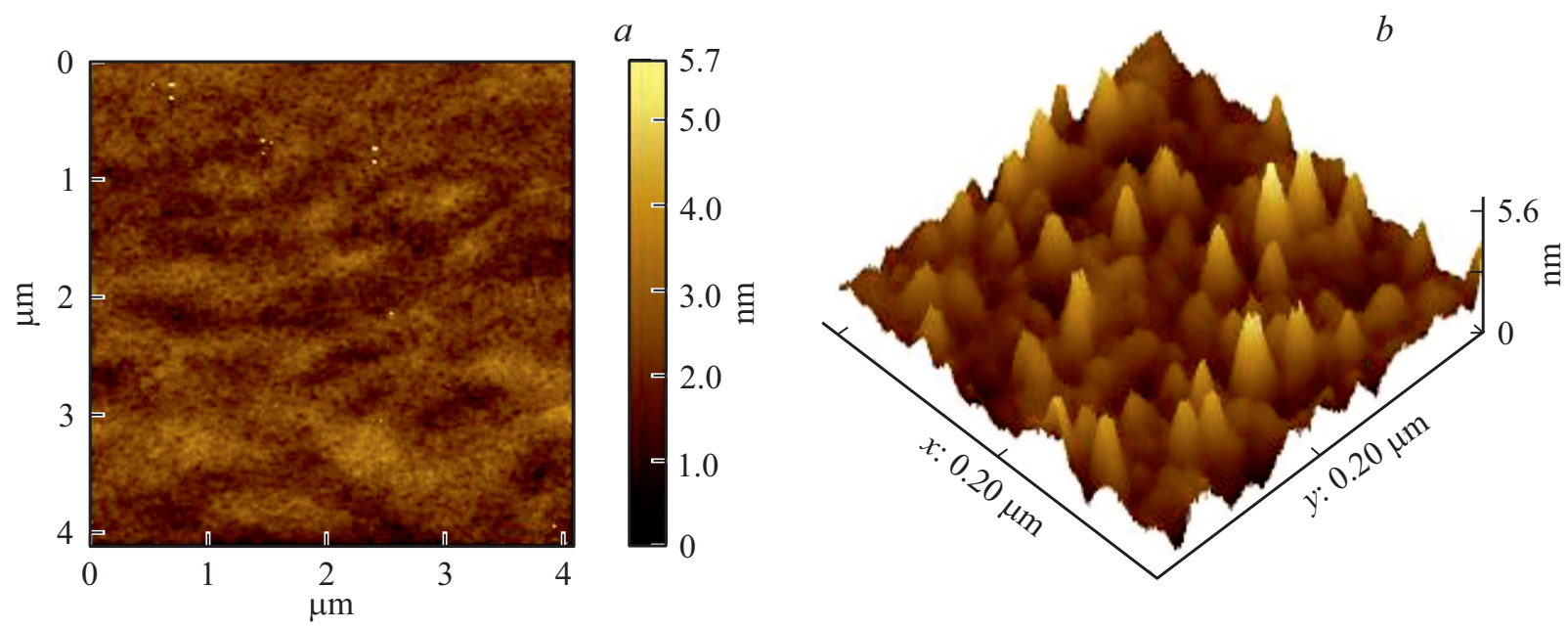

Рис. 3. Результаты АСМ-исследований поверхности углеродных пленок, сформированных $(a)$ на $\mathrm{GaAs}(100)$ и $(b)$ на $\mathrm{Si}(111)$ подложках.

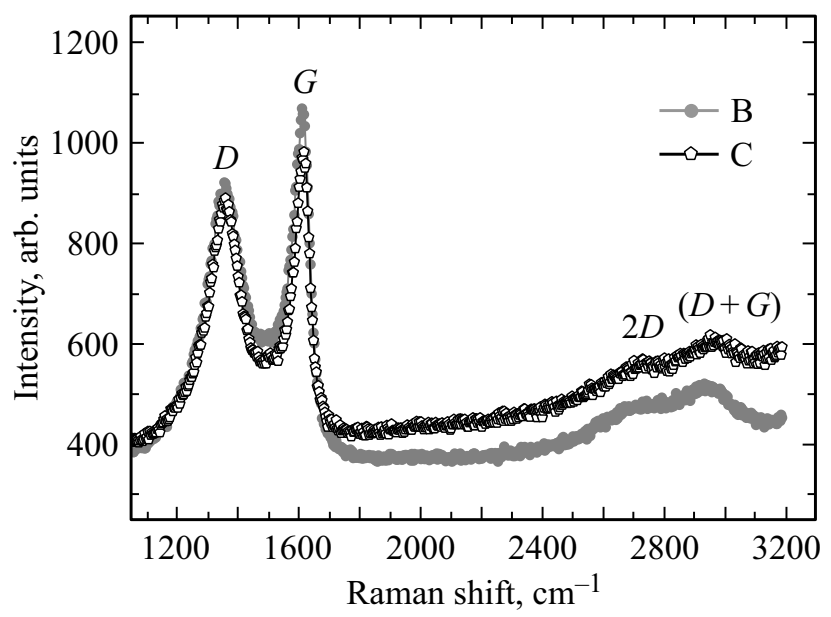

Pис. 4. Спектры КРС углеродных пленок образцов В и С, изготовленных при температуре $650^{\circ} \mathrm{C}$ (табл. 1). Мощность лазера при измерениях равна $0.5 \mathrm{MB}$.

и $G$ в определенной степени характеризует разупорядочение углеродной структуры. Следует отметить, что положение линии $G$ значительно смещено в область больших энергий $\left(1610-1616 \mathrm{~cm}^{-1}\right)$ по отношению к положению линии для монокристаллического графита $1580 \mathrm{~cm}^{-1}$, что также является признаком разупорядочения в слоях, так как в данном случае смещение линии $G$ и ее уширение может быть связано с присутствием линии $D^{\prime}$ выше по энергии, также появляющегося вследствие присутствия дефектов. При значительном разупорядочении линии $G$ и $D^{\prime}$ уширяются и становятся трудноразрешимыми, поэтому их идентифицируют как линия $G$. В спектрах, кроме линий $G$ и $D$, наблюдаются линии $2 D$ (полоса $2 D$ является обертоном второго порядка линии $D)$ и $D+G$. Параметры наблюдаемых линий и их сопоставление с литературными данными $[14,15]$ позволяют предположить, что полученные углеродные слои представляют собой разупорядоченный нанокристаллический графит.

Сопоставление спектров фотолюминесценции контрольной структуры и структуры с углеродным слоем показывает, что интенсивность излучения квантовой ямы уменьшается во втором случае на 2 порядка величины. Интенсивность пика, отвечающего межзонным переходам в буферном слое GaAs, несколько увеличивается. Подобное поведение обусловлено влиянием на излучательную рекомбинацию внутреннего электрического поля $p-n$-перехода, возникающего при формировании углеродного слоя на поверхности структуры, изготовленной на $n^{+}$-GaAs-подложке. Образование $p-n$-перехода подтверждается диодной вольт-амперной характеристикой.

На основе структур с углеродным слоем были изготовлены спиновые светоизлучающие диоды (ССИД). Для этого ферромагнитный сплав $\mathrm{CoPt}$ наносился поверх углеродной пленки, сформированной на арсенид-

Таблица 2. Результаты анализа спектров КРС структур В и С, изготовленных при температуре $650^{\circ} \mathrm{C}$

\begin{tabular}{c|c|c|c|c|c|c|c}
\hline № & $v(G), \mathrm{cm}^{-1}$ & $\operatorname{FWHM}(G), \mathrm{cm}^{-1}$ & $v(G), \mathrm{cm}^{-1}$ & $\operatorname{FWHM}(G), \mathrm{cm}^{-1}$ & $v(2 D), \mathrm{cm}^{-1}$ & $v(D+G), \mathrm{cm}^{-1}$ & $I(D) / I(G)$ \\
\hline B & 1610 & 58 & 1360 & 137 & 2720 & 2946 & 0.777 \\
C & 1610 & 68 & 1360 & 124 & 2728 & 2970 & 0.840
\end{tabular}

Примечание. v - положение фононной линии, а FWHМ - ширина фононной линии на половине ее высоты. 


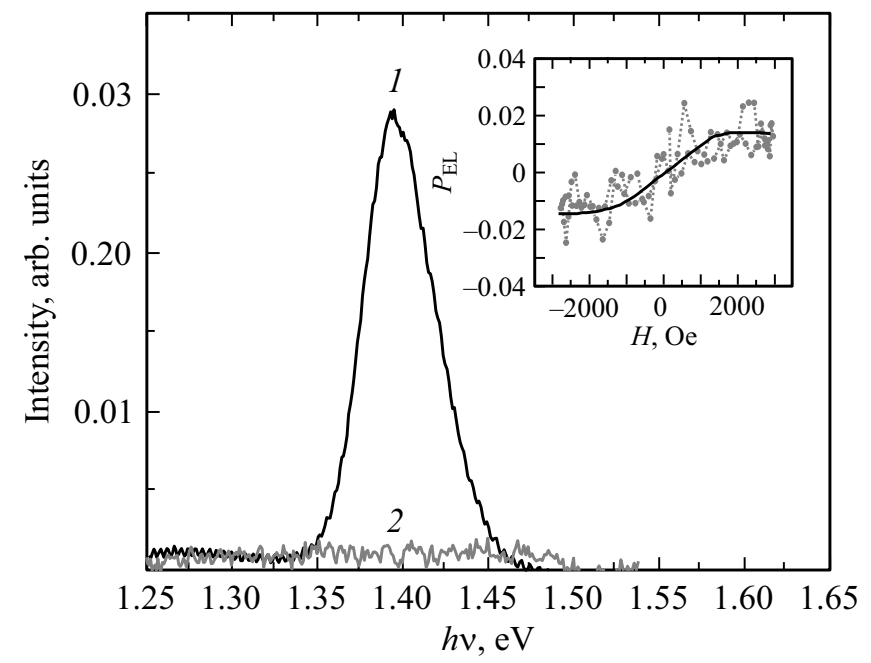

Рис. 5. Спектры электролюминесценции диода $\mathrm{CoPt} / \mathrm{C}-$ слой/ $\mathrm{GaAs} / \mathrm{K}$ InGaAs (структура D, спектр 1 ) и диода $\mathrm{CoPt} / \delta$-легированный C покровный слой GaAs/KЯ InGaAs (спектр 2) при токе $I=80 \mathrm{MA}$ и температуре $77 \mathrm{~K}$. На вставке приведена магнитополевая зависимость степени циркулярной поляризации электролюминесцентного излучения структуры D при температуре $10 \mathrm{~K}$. Величина тока равна $100 \mathrm{MA}$.

галлиевой структуре с квантовой ямой InGaAs, через маску методом электронно-лучевого испарения в вакууме при температуре $200-300^{\circ} \mathrm{C}$. Затем с использованием методов фотолитографии и химического травления формировались мезаструктуры диодов диаметром 500 мкм. Полученные диоды демонстрировали электролюминесцентное излучение в области квантовой ямы (рис. 5) в отличие от ССИД, изготовленных с использованием сплава CoPt и арсенид-галлиевой структуры с $\delta$-слоем углерода в покровном слое GaAs (рис. 5).

Наблюдаемая разница в спектрах электролюминесценции позволяет полагать, что углеродный слой может выполнять функцию диффузионного барьера, препятствуя проникновению атомов кобальта из слоя $\mathrm{CoPt}$ в активную область светодиода. Исследование поляризационных свойств излучения ССИД при $10 \mathrm{~K}$ обнаружило, что излучение квантовой ямы InGaAs было циркулярно-поляризованным благодаря инжекции в нее спин-поляризованных носителей. Из представленной на вставке рис. 5 магнитополевой зависимости степени циркулярной поляризации видно, что степень поляризации достигала 1\% в магнитном поле 2000 Э.

\section{4. Заключение}

Впервые предложен и реализован метод формирования углеродных слоев термическим разложением четыреххлористого углерода в реакторе МОС-гибридной эпитаксии при атмосферном давлении и температурах в диапазоне от 560 до $700^{\circ} \mathrm{C}$. Полученные углеродные пленки на поверхности арсенид-галлиевых структур имели гладкую поверхность, были механически прочными и демонстрировали дырочную проводимость. Исследования спектроскопии комбинационного рассеяния света позволяют предположить, что полученные разработанным методом углеродные слои представляют собой разупорядоченный нанокристаллический графит. Показана возможность использования такого углеродного слоя в технологическом цикле создания GaAsприборных структур оптоэлектроники (в частности, спиновых светоизлучающих диодов с инжектором $\mathrm{CoPt}$ ). Обнаружено, что на поверхности $\mathrm{Si}$ при разложении $\mathrm{CCl}_{4}$ формируется игольчатая структура (подобно вертикальному графену), которая может иметь перспективы применения в эмиссионной электронике.

\section{Финансирование работы}

Работа выполнена при частичной поддержке РФФИ (грант № 18-29-19137_мк). Изготовление структур спиновых светоизлучающих диодов было реализовано при поддержке Российского научного фонда (грант № 17-79-20173).

\section{Конфликт интересов}

Авторы заявляют, что у них нет конфликта интересов.

\section{Список литературы}

[1] L. Wang, W. Liu, Y. Zhang, Z.-H. Zhang, S.T. Tan, X. Yi, G. Wang, X. Sun, H. Zhu, H.V. Demir. Nano Energy, 12, 419 (2015).

[2] B.-J. Kim, C. Lee, Y. Jung, K.H. Baik, M.A. Mastro, J.K. Hite, C.R. Eddy, jr., J. Kim. Appl. Phys. Lett., 99, 143101 (2011).

[3] X. Wang, L. Zhi, K. Mullen. Nano Lett., 8, 323 (2008).

[4] S.-I. Na, S.-S. Kim, J. Jo, D.-Y. Kim. Adv. Mater., 20, 4061 (2008).

[5] А.В. Бабичев, В.Ю. Бутко, М.С. Соболев, Е.В. Никитина, Н.В. Крыжановская, А.Ю. Егоров. ФТП, 46 (6), 815 (2012).

[6] A.V. Babichev, H. Zhang, P. Lavenus, F.H. Julien, A.Yu. Egorov, Y.T. Lin, L.W. Tu, M. Tchernycheva. Appl. Phys. Lett., 103, 201103 (2013).

[7] А.В. Бабичев, H. Zhang, N. Guan, А.Ю. Егоров, F.H. Julien, A. Messanvi, C. Durand, J. Eymery, M. Tchernycheva. ФТП, 50 (8), 1118 (2016).

[8] L.-B. Luo, H. Hu, X.-H. Wang, R. Lu, Y.-F. Zou, Y.-Q. Yu, F.-X. Liang. J. Mater. Chem. C, 3, 4723 (2015).

[9] J. Wu, Z. Yang, C. Qiu, Y. Zhang, Z. Wu, J. Yang, Y. Lu, J. Li, D. Yang, R. Hao, E. Li, G. Yuf, Sh. Lin. Nanoscale, 10, 8023 (2018).

[10] А.А. Мармалюк. Разработка процесса МОС-гидридной эпитаксии квантово-размерных гетероструктур на основе полупроводников $\mathrm{A}^{\mathrm{III}} \mathrm{B}^{\mathrm{V}}$ для приборов оптоэлектроники и ИК-техники / Дис. докт. техн. наук (М., 2006).

[11] Ю.И. Уханов. Оптические свойства полупроводников (М., Наука, 1977).

[12] D.H. Seo, A.E. Rider, S. Kumar, L.K. Randeniya, K. Ostrikov. Carbon, 60, 221 (2013). 
[13] K. Davami, J. Cortes, N. Hong, I. Bargatin. Mater. Res. Bull., 74, 226 (2016).

[14] A.C. Ferrari. Solid State Commun., 143, 47 (2007).

[15] A.C. Ferrari, J. Robertson. Phys. Rev. B, 61 (20), 14095 (2000).

Редактор А.Н. Смирнов

\section{The formation of carbon layers by thermal decomposition of carbon tetrachloride in the reactor MOCVD epitaxy}

B.N. Zvonkov' ${ }^{1}$, O.V. Vikhrova' ${ }^{1}$, Yu.A. Danilov', M.V. Dorokhin ${ }^{1}$, P.B. Demina ${ }^{1}$, M.N. Drozdov ${ }^{2}$, A.V. Zdoroveyshchev ${ }^{1}$, R.N. Kriukov ${ }^{1}$, A.V. Nezhdanov ${ }^{3}$, I.N. Antonov ${ }^{1}$, S.M. Plankina ${ }^{3}$, M.P. Temiryazeva ${ }^{4}$

${ }^{1}$ Physical Technical Research Institute of the Lobachevsky State University of Nizhny Novgorod, 603950 Nizhny Novgorod, Russia

2 Institute for Physics of Microstructures,

Russian Academy of Sciences, 603950 Nizhny Novgorod, Russia

${ }^{3}$ Lobachevsky State University of Nizhny Novgorod, 603950 Nizhny Novgorod, Russia ${ }^{4}$ Fryazino Branch of the V.A. Kotelnikov Institute of Radio Engineering and Electronics, Russian Academy of Sciences, 141190 Fryazino, Moscow region, Russia

Abstract The new method for deposition of carbon films by thermal decomposition of carbon tetrachloride $\left(\mathrm{CCl}_{4}\right)$ with a hydrogen flow in an atmospheric pressure MOCVD epitaxy reactor has been developed. The results of Raman spectroscopy studies suggest that the obtained by this method carbon layers are disordered nanocrystalline graphite. The possibility of using such a carbon layer in the technological cycle of creating gallium arsenide device structures of optoelectronics (in particular, spinlightemitting diodes with a CoPt injector) is shown. 